\title{
Attributable fraction of tobacco smoking on cancer deaths from 2010 to 2019 using mortality case-control study in Tianjin, China
}

\author{
Wei LI ( $\square$ liweicdc@126.com ) \\ Tianjin Centers for Disease Control and Prevention \\ XUE Xiaodan \\ Tianjin Centers for Disease Control and Prevention \\ LI Dandan \\ Tianjin Centers for Disease Control and Prevention \\ Ying ZHANG \\ Tianjin Centers for Disease Control and Prevention \\ Wenda SHEN \\ Tianjin Centers for Disease Control and Prevention \\ JIANG Guohong \\ Tianjin Centers for Disease Control and Prevention
}

\section{Research Article}

Keywords: Risk factor, Smoking-attributed death, Lifestyle, Asia, China, Mortality Case-control Study

Posted Date: August 17th, 2021

DOI: https://doi.org/10.21203/rs.3.rs-819145/v1

License: (c) (i) This work is licensed under a Creative Commons Attribution 4.0 International License. Read Full License 


\section{Abstract}

Background: Smoking is by far the most important cause of cancer that can be modified at the individual level. Asia has a high incidence of cancer incidence and death, while China has the highest incidence in Asia, and accounting for $27 \%$ of the world's cancer deaths. The purpose of the current study was to perform an evidence-based assessment of the burden of tobacco smoking-related cancers death in the Tianjin, China.

Methods: A mortality case-control study to assess the risks of all-cause and major causes of cancer death attributable to smoking from 2010 to 2019.

Results: Tobacco smoking was responsible for 23,709 (28.87\%) cancer deaths among adult men and 8,648 (13.37\%) among adult women in 2010 to 2019 in Tianjin. Lung cancer remains the largest cause of cancer death. In men, $49.06 \%$ of lung cancer, $27.55 \%$ of upper aerodigestive cancer, $10.11 \%$ of liver, $13.56 \%$ of kidney and other urinary cancer deaths were attributable to tobacco smoking. In women the proportion of ever-smoking-attributable lung cancer was $31.56 \%, 10.59 \%$ of upper aerodigestive and $10.56 \%$ of bladder cancer deaths. By year, smoking-attributable cancer deaths in men increased from 1817 in 2010 to 2695 in 2019; for women, the number remained stable at just over 800 per year.

Conclusions: Approximately one in three cancer deaths in men and one in six cancer deaths in women would be potentially preventable through appropriate control of tobacco smoking in Tianjin. Effective control programs against tobacco smoking should be further implemented.

\section{Background}

Cancer has become the largest public health problem in the world [1], and the prevention and treatment of malignant tumors in China is also very serious. Asia has a high incidence of cancer incidence and death, while China has the highest incidence in Asia. The results of the survey of China's cancer death from 2004 to 2005 showed that the mortality rate of cancer in China increased by $83.1 \%$ compared with that in the mid 1970 s, and $22.5 \%$ higher than that in the early 1990s. According to the statistics of the world cancer report [3], in 2012, China accounted for $20 \%$ of the world's new malignant tumor cases, $22 \%$ of the world's cancer cases and $25 \%$ of the world's deaths.

Smoking is by far the most important cause of cancer that can be modified at the individual level. More than one in four male cancer deaths ( $29 \%$ ) and one in five female cancer deaths (20\%) could be attributed to smoking in 2008 [4].

Tianjin is one of the largest and most developed cites in China. We have a more sophisticated and reliable system of death registration than most cities in China and other low- and middle-income countries. The Tianjin All Causes of Death Registration System (CDRS) was established in 1984, which now covers the entire population of approximately 10 million (as in 2013) with $40 \%$ urban and $60 \%$ rural residents [5]. The leading causes of death were cardiovascular disease, cancer, and respiratory disease in Tianjin, China. Through this system, all causes of death should be reported, and all death certificates entered into the database must be completed by physicians in hospitals or community health service centers. Each death certificate has approximately 50 data fields, including age, sex, education, and cause of death, as well as the home address for classifying area of residence as urban or rural. Starting at the end of 2009 , Tianjin Centers for Disease Control and Prevention (TJCDC) has been collecting information routinely on smoking (including 3 questions) of the deceased in the death certificate. This is the first and only death registration system in China doing so. Tianjin, being the second to include smoking in death registration in the world after South Africa, collects more information on smoking than South Africa. Then Tianjin developed the mortality case-control (MCC) studies use the information collected from CDRS since 2010 [6].

The purpose of the current study was to perform an evidence-based assessment of the burden of tobacco smoking-related cancers death in the Tianjin, China.

\section{Methods}

\section{Definition of case and control}

We included deaths $\geq 35$ age years old in 2010 through 2019 . We excluded deaths at 34 years or younger because smoking was expected to cause very few deaths at a young age caused by smoking could be less reliable. We followed the methods of Sitas et al [7], and the definition of cases and controls were according to the American Cancer Society's A Report of the Surgeon General [8]. Cases were deaths from 9 groups of cancers that are causally or strongly associated with smoking, including lung, upper aerodigestive, stomach, liver, pancreas, bowel, kidney and other urinary, Bladder, myeloid leukemia. Controls were deaths from all other specified diseases that were not confirmed to be caused by or were not strongly associated with smoking. III-defined and unknown causes were also excluded. The cases were current and former smokers and controls were never smokers.

Tobacco smoking status was classified as "never", "former", and "current" in this study. We used the term "ever-smoking" to mean "former" or "current" smoking.

\section{Relative risk of tobacco smoking and estimation of population attributed fraction (PAF)}

Unmatched multiple logistic regression was used to calculate risk ratios (RR) or mortality rate ratio of all-cause and cause-specific death in ever smokers versus never smokers adjusted by 5-year age group, education (none, primary, higher, do not know), marital status (never, widowed, divorced, married or living as married, do not know), and year of death (single year from 2010 through 2019).

If $D$ is the total number of deaths (from a particular disease) in smokers, then the number of deaths attributed to smoking, Ds, can be calculated separately for men and women as $\mathrm{Ds}=\mathrm{D}(1-1 \div \mathrm{RR})$, where RR is risk ratio (to estimate relative risk), where Ds is positive, Ds divided by the total number deaths in the whole population gives the PAF of smoking [9]. Where Ds are negative, the fraction could be due to the "protective" effect of smoking. Attributable numbers for groups of diseases (and for overall mortality) were derived from the sum of the number of each specific disease within the group.

Page 2/8 
Men and women were analyzed separately. Statistical tests and 2-sided 95\% confidence intervals (Cls) were based on changes in log-likelihood. When the $95 \%$ $\mathrm{Cl}$ for the relative risk in men did not overlap with that in women, the sex difference was significant at P less than .05 levels. Otherwise, the interaction of sex and smoking was tested by adding an interaction term in the model. All analyses were performed with SPSS 23.0 (SPSS Inc).

\section{Sensitivity analysis for the estimation of PAF of tobacco smoking}

To account for the uncertainty in PAF estimation arising from the estimation of RRs for each cancer site, a sensitivity analysis was performed under alternative scenarios using the lower and upper limits of the $95 \%$ Cls of RR estimates.

\section{Results}

\section{Relative risk of tobacco smoking}

Among all cancer sites reviewed in this study, the total RR for ever smoking was respectively 1.861 and 2.380 in men and women (Table 1). Top three RR among ever smokers' men was lung cancer (3.061, 2.956-3.170), upper aerodigestive cancer $(1.798,1.698-1.904)$, kidney and other urinary cancer (1.333, 1.210-1.468) respectively. And among ever smokers' women were lung cancer (3.870, 3.703-4.045), upper aerodigestive cancer (1.708, 1.536-1.899) and bladder cancer $(1.679,1.416-1.991)$. The RRs for ever smokers ranged from 1.078 to 3.870 for cancer mortality, except for a few cases where the RR was estimated to be less than one with insignificant p-values (Table 1).

Table 1 Mortality Rate Ratio at Age $\geq 35$ Years, Selected Cancer Causes, Ever Smokers Versus Never Smokers, Tianjin, China, 2010-2019

\section{Smoking-attributable cancer deaths by age and cancer type}

Tobacco smoking was responsible for 23,709 (28.87\%) cancer deaths among adult men and 8,648 (17.37\%) cancer deaths among adult women among 2010 to 2019 in Tianjin, China (Table 2). As expected, lung cancer comprised the greatest proportion of all smoking-related cancer deaths both in men and women. In men, nearly $50 \%$ of lung cancer deaths, $27.55 \%$ of upper aerodigestive cancer deaths, $10.11 \%$ of liver, $8.08 \%$ of stomach, $8.36 \%$ of pancreas, $13.56 \%$ of kidney and $12.35 \%$ of bladder cancer deaths were attributable to tobacco smoking. In women, however, ever-smoking-attributable lung cancer deaths were $31.56 \%$ of the total lung cancer deaths. $10.59 \%$ of upper aerodigestive cancer deaths, $10.11 \%$ of liver, $8.08 \%$ of stomach, $10.56 \%$ of bladder cancer deaths were attributable to tobacco smoking. In women, the ever-smoking attributable death in 2010,2014 and 2019 was respectively $20.62 \%, 16.72 \%$ and $16.30 \%$, taking on a decreasing change. But could not found a same trend in men, the ever-smoking attributable death was $27.31 \%, 30.59 \%$ and $29.22 \%$ in the above three years (Table 2).

Table 2 Number of smoking-attributable cancer deaths and attributable fraction by site, Tianjin, China, 2010-2019

The smoking rate of men in the study remained stable for 10 years (average: $62.39 \%$ ), while women showed a downward trend (from $35.33 \%$ to $27.58 \%$ ).

The annual number of smoking-attributable cancer deaths among women has remained relatively constant at around 800 each year since the 2010 s (Figure 1), despite the population growth and ageing during this time. The number of smoking-attributable cancer deaths in 55-74 year old women decreased by $31.81 \%$ and in $\geq 75$ year old increase by $20.77 \%$, between 2010 and 2019 (Table 3). The annual number of smoking-attributable cancer deaths among men has gradual growth from 1822 to 2684 (increase by 47.3\%) between 2010 and 2019 (Figure 1 and Table 3). The number of smoking-attributable cancer deaths in $35-54,55-74, \geq 75$ years old men increased by $27.40 \%, 82.31 \%$ and $11.56 \%$ respectively between 2010 and 2019 (Table 3 ). The greatest increase in the annual number of smoking attributable cancer deaths was in men 55-74 years of age with a more the one fold increase between 2010 ( $\mathrm{n}=978$ ) and 2019 $(n=1786)$.

Figure 1 Smoking-attributable cancer deaths by age group, males and females, Tianjin, China, 2010-2019

Table 3 Number of smoking-attributable cancer deaths and attributable fraction by age, 2010, 2014, 2019

\section{Sensitivity analysis for the estimation of PAF of tobacco smoking}

Sensitivity analysis showed that the PAF estimates were more sensitive to the variation in RR in women than in men when the upper and lower limits of the $95 \% \mathrm{Cl}$ of RR was used, due to the larger uncertainty in the estimation of RRs for women, particularly for stomach and pancreas (Figure 2).

Figure 2 Sensitivity analysis of the PAF for ever-smoking using the lower and upper limits of $95 \%$ confidence interval for relative risks

\section{Discussion}

Our study provides a systematic assessment of the burden of smoking-related cancer in Tianjin, China among 2010 to 2019 . RR for eve-smokers death from lung cancer in men was 3.061 (2.956-3.170), was similar with the nationwide prospective cohort studies result (2.98, 2.66-3.33). But the RR for women was higher in our study $(3.870,3.703-4.045$ vs. 2.56, 2.02-3.26) [10]. The RR for women death from lung cancer in Tianjin was similar with Japan and Korea which was 3.6 and 3.2 respectively [11]. But the results were much lower than France and United Kingdom.

Overall, 32,357 of 131,919 (24.53\%) cancer deaths were attributable to tobacco smoking in Tianjin. There was a large discrepancy between men and women in the PAF estimates of cancer mortality ( $28.87 \%$ vs. $17.37 \%)$, which was a little lower to previous reports in men in Korea (32.9\%), Japan (34.4\%), France (33.4\%) and much higher to above country, Korea (5.2\%), Japan (6.2\%), France (9.6\%) [11-13]. It much similar to United Kingdom, that PAF was 23.0\% and $15.6 \%$ in men and women respectively. Our results suggest that Tianjin women have the highest percentage of all-cause and lung cancer deaths attributable to 
smoking in China, probably because of their high smoking prevalence. The First National Smoking Prevalence Survey in 1984 showed that the smoking prevalence was $7.04 \%$ in women in China, while the prevalence of $27.4 \%$ in Tianjin women was the highest [14]. Also we found that the number of smokingattributable cancer deaths in $\geq 75$ year old increase from 467 to 564 between 2010 and 2019. That was also because the smoking prevalence of the women born before year 1935 was higher than the women born after 1935.

These results of comparison support the necessity of ethnic- or country-specific evaluation of the PAF because even though the overall PAF appear to be same, the exposure prevalence and the RRs can be different across countries or districts, therefore, the prevention strategy in each country or district should be different. It is very important to monitor and calculate RR and PAF in country and region level for formulating targeted prevention and control strategies.

Due to the significant decrease of smoking rate in women [15-17], it can be observed that the smoking attributable lung cancer death in women decreased from $36.6 \%$ in 2010 to $29.6 \%$ in 2019 , but it remained stable in men. Since the majority of lung cancers are attributable to smoking, changes in smoking prevalence are the key driver of lung cancer mortality trends. In particular, $49.06 \%$ of all lung cancer deaths in Tianjin among more than 35 years old men could have been prevented if no man had smoked in Tianjin, and the percentage was $31.56 \%$ in women.

The MCC study which developed in the Tianjin design can be a quick, efficient, and reliable method to assess and monitor mortality risks of smoking, and it can be promoted in other cities or countries with a reliable system of death certification and good quality control measures like the Tianjin CDRS. Use of RRs from the MCC study in Tianjin can measure the data of more accurately smoking-attributable death than the general RRs from the global study, such as GBD and et al.

Our findings highlight the high risks of cancer deaths, mainly from lung cancer and upper aerodigestive cancer, in men and women ever smokers and particularly the high proportion of deaths attributable to smoking in women in Tianjin, which had the highest smoking prevalence among women around the 1980 s in China. Strong tobacco control measures are needed to motivate a large proportion of smokers, including female smokers, to stop smoking. Special and urgent warnings and tobacco control campaigns are needed to prevent the increase in smoking in young women. In countries, regions, or cities with a reliable system of death certification, the mortality case-control study design using routinely collected smoking data from death certificates can be used to rapidly and periodically assess the mortality risks of smoking and evaluate the effects of tobacco control measures at different stages of the tobacco use epidemic.

This Tianjin study is China's first mortality case-control study based on smoking data from death registration. Lung cancer was the main cause (half in men and two-thirds in women) of smoking-induced deaths. The smoking-attributed fractions of all-cause and lung cancer deaths in women were the greatest probably because of the high smoking prevalence among woman in the city around the $1980 \mathrm{~s}$. The mortality case-control study design can be used to rapidly and periodically assess the mortality risks of smoking and evaluate the effects of tobacco control measures.

\section{Conclusions}

While the smoking prevalence in male adults has been decreasing in Tianjin, China, it remains high (more than $25 \%$ in people aged 15 and above). Because Tianjin is quickly approaching the status of an aged society, the number of cancer cases and deaths are expected to increase in the future. Approximately one in three cancer deaths in men and one in six cancer deaths in women would be potentially preventable through appropriate control of tobacco smoking in Tianjin. Effective tobacco control programs should be further developed and implemented in Tianjin to reduce the smoking-related cancer burden.

\section{Implications}

Our study provides a systematic assessment of the burden of smoking-related cancer by mortality case-control study in Tianjin, China among 2010 to 2019. RR for eve-smokers death from lung cancer in men was 3.061 (2.956-3.170), was similar with the nationwide prospective cohort studies result (2.98, 2.663.33). But the RR for women was higher in our study (3.870, 3.703-4.045 vs. 2.56, 2.02-3.26) than the whole China, but similar with Japan and Korea. Overall, 32,357 of $131,919(24.53 \%)$ cancer deaths were attributable to tobacco smoking in Tianjin. There was a large discrepancy between men and women in the PAF estimates of cancer mortality (28.87\% vs. $17.37 \%)$. These results of comparison support that it is very important to monitor and calculate RR and PAF in country and region level for formulating targeted prevention and control strategies. Because Tianjin is quickly approaching the status of an aged society, the number of cancer cases and deaths are expected to increase in the future. Approximately one in three cancer deaths in men and one in six cancer deaths in women would be potentially preventable through appropriate control of tobacco smoking in Tianjin. Effective tobacco control programs should be further developed and implemented in Tianjin to reduce the smoking-related cancer burden.

\section{Declarations}

\section{Competing interests}

The authors declare that they have no competing interests.

\section{Author's contributions}

LI Wei and XUE Xiaodan wrote the main manuscript text, tables and figures; LI Dandan, ZHANG Ying and SHEN Wenda cleaned up the data; JIANG Guohong gave the guidance to analyses. All authors reviewed the manuscript.

\section{Acknowledgements}


We thank all staff who are involved in the Tianjin CDRS, local CDCs, hospitals, and community health service centers. We do not use copyrighted material and copyrighted surveys, instruments, or tools in our study.

This study was implemented as a register-based study based on anonymous data at TJCDC CDC and was approved by the TJCDC Ethics Committee. Registerbased studies on anonymous data do not require written consent in Tianjin. There was no funding for this study.

\section{References}

1. Duan JJ, Chen WQ, Zhang SW. International Comparison of Maligant Tumor Mortality [J]. Chi J of Social Med, 2009,26(6): 377-378.

2. Zhang WD, Miao SJ. Analysis on epidemic characteristics of cancer death rate in China [J]. Chi J of Health Education, 2009, 25(4): 246-248.

3. Stewart BW, Wild CP. World cancer report 2014[M].Lyons: International agency for research on cancer,2014.

4. Creighton N, Perez D, Cotter T. Smoking-attributable cancer mortality in NSW, Australia, 1972-2008. Public Health Res Pract. 2015;25(3):e2531530. doi: http:// dx.doi.org/10.17061/phrp2531530

5. Li Wei, Jiang Guo-hong, Wang De-zheng, Zhang Hui, Xu Zhong-liang, Zhang Ying, Zheng Wen-long, Xue Xiao-dan, Peto Richard, Lam Tai-Hing. Smoking and mortality in Tianjin, China: a death registry based case-control study of 180,000 adult deaths from 2010 to 2014. Preventing Chronic Disease. Prev Chronic Dis 2018;15:170577. DOI: http://dx.doi.org/10.5888/pcd15.170577

6. Jiang G, Zhang H, Li W, Wang D, Xu Z, Song G, et al. [Study on smoking-attributed mortality by using all causes of death surveillance system in Tianjin]. Zhonghua Liu Xing Bing Xue Za Zhi 2016;37(3):381-3. Chinese. PubMed

7. Sitas F, Egger S, Bradshaw D, Groenewald P, Laubscher R, Kielkowski D, et al. Differences among the coloured, white, black, and other South African populations in smoking-attributed mortality at ages 35-74 years: a case-control study of 481,640 deaths. Lancet 2013;382(9893):685-93. PubMedhttp://dx.doi.org/10.1016/S0140-6736(13)61610-4

8. Brawley, O. W., et al. "The first surgeon general's report on smoking and health: The 50th anniversary." Ca A Cancer Journal for Clinicians 64.1(2014).

9. Liu BQ, Peto R, Chen ZM, Boreham J, Wu YP, Li JY, et al. Emerging tobacco hazards in China: 1. Retrospective proportional mortality study of one million deaths. BMJ 1998;317(7170):1411-22. PubMedhttp://dx.doi.org/10.1136/bmj.317.7170.1411】]

10. Zhengming Chen,Richard Peto,Maigeng Zhou, et al. Contrasting male and female trends in tobacco-attributed mortality in China: evidence from successive nationwide prospective cohort studies[J]. Lancet 2015; 386: 1447-56. DOI: https://doi.org/10.1016/S0140-6736(15)00340-2

11. Inoue M, Sawada N, Matsuda T, Iwasaki M, Sasazuki S, Shimazu T, Shibuya K, Tsugane S: Attributable causes of cancer in Japan in 2005-systematic assessment to estimate current burden of cancer attributable to known preventable risk factors in Japan. Ann Oncol 2012, 23(5):1362-1369.

12. Park S, Sun H J, Shin H R, et al. Attributable fraction of tobacco smoking on cancer using population-based nationwide cancer incidence and mortality data in Korea[J]. BMC Cancer,14,1(2014-06-06), 2014, 14(1):1-12.

13. International Agency for Research on Cancer: Attributable causes of cancer in France in the year 2000. Lyon, France: IARC; 2007.

14. Weng XZ, Hong ZG, Chen DY. Smoking prevalence in Chinese aged 15 and above. Chin Med J (Engl) 1987;100(11):886-92. PubMed

15. Weng XZ, Hong ZG, Chen DY. Smoking prevalence in Chinese aged 15 and above. Chin Med J (Engl) 1987;100(11):886-92. PubMed.

16. Li Q, Hsia J, Yang G. Prevalence of smoking in China in 2010. N Engl J Med 2011;364(25):2469-70. PubMed http://dx.doi.org/10.1056/NEJMc1102459.

17. Chen Chuan,Huang Yubei,Liu Xueou. Current status of smoking and passive smoking among aged 45 to 65 years old females in five cities of China. Chin J Epidemiol,2014(35):797-801. DOI: 10.3760/cma.j.issn.0254-6450.2014.07.009

\section{Tables}

Table 1 Mortality Rate Ratio at Age $\geq 35$ Years, Selected Cancer Causes, Ever Smokers Versus Never Smokers, Tianjin, China, 2010-2019 


\begin{tabular}{|c|c|c|c|c|c|c|c|c|c|c|c|c|c|c|}
\hline Sex & Site (ICD-10 Code) & 2010 & $95 \% \mathrm{Cl}$ & & & 2014 & $95 \% \mathrm{Cl}$ & & & 2019 & $95 \% \mathrm{Cl}$ & & & Tota \\
\hline \multirow[t]{9}{*}{ Male } & Lung (C33-4) & 3.013 & 2.644 & & 3.434 & 3.166 & 2.833 & , & 3.537 & 3.162 & 2.852 & , & 3.505 & 3.06 \\
\hline & Upper aerodigestive $(\mathrm{COO}-15, \mathrm{C} 32)$ & 1.365 & 1.111 & , & 1.677 & 1.905 & 1.589 & , & 2.284 & 1.904 & 1.604 & , & 2.259 & 1.79 \\
\hline & Stomach(C16) & 1.070 & 0.895 & , & 1.280 & 1.202 & 1.024 & , & 1.412 & 1.131 & 0.966 & , & 1.324 & 1.18 \\
\hline & Liver(C22) & 1.165 & 0.996 & , & 1.363 & 1.339 & 1.157 & , & 1.549 & 1.214 & 1.053 & , & 1.400 & 1.22 \\
\hline & Pancreas(C25) & 1.036 & 0.806 & , & 1.332 & 1.436 & 1.158 & , & 1.780 & 1.120 & 0.926 & , & 1.354 & 1.18 \\
\hline & Bowel(C18-21) & 0.987 & 0.801 & , & 1.217 & 1.213 & 1.021 & , & 1.440 & 1.023 & 0.879 & , & 1.191 & 1.07 \\
\hline & Kidney and other urinary $(\mathrm{C} 64-6, \mathrm{C} 68)$ & 1.112 & 0.762 & , & 1.624 & 1.755 & 1.288 & , & 2.392 & 1.237 & 0.950 & , & 1.611 & 1.33 \\
\hline & Bladder(C67) & 1.580 & 1.134 & , & 2.201 & 1.309 & 0.998 & , & 1.718 & 1.419 & 1.112 & , & 1.810 & 1.32 \\
\hline & $\begin{array}{l}\text { Myeloid } \\
\text { leukemia(C92,C93.0,C94.0,C94.2,C94.4- } \\
\text { 5) }\end{array}$ & 1.062 & 0.466 & , & 2.422 & 0.821 & 0.416 & , & 1.618 & 0.794 & 0.431 & , & 1.462 & 1.01 \\
\hline Total & & 1.745 & 1.563 & , & 1.948 & 1.987 & 1.806 & , & 2.186 & 1.846 & 1.693 & , & 2.013 & 1.86 \\
\hline \multirow[t]{10}{*}{ Female } & Lung (C33-4) & 4.046 & 3.483 & , & 4.700 & 3.699 & 3.200 & , & 4.276 & 3.964 & 3.471 & , & 4.529 & 3.87 \\
\hline & Upper aerodigestive (C00-15,C32) & 1.890 & 1.359 & , & 2.630 & 1.464 & 1.033 & , & 2.076 & 2.032 & 1.458 & , & 2.831 & 1.70 \\
\hline & Stomach(C16) & 1.135 & 0.842 & , & 1.528 & 1.048 & 0.770 & , & 1.425 & 1.161 & 0.861 & , & 1.566 & 1.09 \\
\hline & Liver(C22) & 1.257 & 0.991 & , & 1.595 & 1.001 & 0.759 & , & 1.319 & 1.422 & 1.095 & , & 1.846 & 1.21 \\
\hline & Pancreas(C25) & 1.475 & 1.084 & , & 2.007 & 1.218 & 0.890 & , & 1.668 & 1.343 & 1.018 & , & 1.771 & 1.16 \\
\hline & Bowel(C18-21) & 0.970 & 0.717 & , & 1.312 & 0.899 & 0.677 & , & 1.194 & 1.138 & 0.892 & , & 1.451 & 0.97 \\
\hline & Kidney and other urinary(C64-6,C68) & 0.680 & 0.327 & , & 1.415 & 1.196 & 0.688 & , & 2.078 & 1.028 & 0.619 & , & 1.706 & 1.12 \\
\hline & Bladder(C67) & 1.513 & 0.810 & , & 2.823 & 1.881 & 1.085 & , & 3.261 & 1.647 & 0.997 & , & 2.719 & 1.67 \\
\hline & $\begin{array}{l}\text { Myeloid } \\
\text { leukemia(C92,C93.0,C94.0,C94.2,C94.4- } \\
\text { 5) }\end{array}$ & 0.333 & 0.042 & , & 2.659 & - & - & , & - & 0.797 & 0.187 & , & 3.396 & 0.78 \\
\hline & Cervix(C53) & 1.009 & 0.503 & , & 2.024 & 1.049 & 0.611 & , & 1.802 & 1.192 & 0.725 & , & 1.960 & 1.10 \\
\hline Total & & 2.402 & 2.096 & , & 2.752 & 2.296 & 2.007 & , & 2.626 & 2.445 & 2.168 & , & 2.757 & 2.38 \\
\hline
\end{tabular}

Table 2 Number of smoking-attributable cancer deaths and attributable fraction by site, Tianjin, China, 2010-2019 


\begin{tabular}{|c|c|c|c|c|c|c|c|c|c|c|c|c|c|}
\hline \multirow[b]{2}{*}{ Sex } & \multirow[b]{2}{*}{ Site (ICD-10 Code) } & \multicolumn{2}{|l|}{2010} & \multicolumn{3}{|c|}{2014} & \multicolumn{3}{|c|}{2019} & \multicolumn{3}{|c|}{ Total } & \multirow[b]{2}{*}{ (\%) } \\
\hline & & $\begin{array}{r}\text { Current } \\
\text { and ever } \\
\text { (\%) }\end{array}$ & $\begin{array}{l}\text { No. } \\
\text { Attributed } \\
\text { to Smoking }\end{array}$ & (\%) & $\begin{array}{r}\text { Current } \\
\text { and ever } \\
(\%)\end{array}$ & $\begin{array}{l}\text { No. } \\
\text { Attributed } \\
\text { to Smoking }\end{array}$ & (\%) & $\begin{array}{r}\text { Current } \\
\text { and } \\
\text { ever }(\%\end{array}$ & $\begin{array}{l}\text { No. } \\
\text { Attributed } \\
\text { to } \\
\text { Smoking }\end{array}$ & (\%) & $\begin{array}{r}\text { Current } \\
\text { and } \\
\text { ever }(\%\end{array}$ & $\begin{array}{l}\text { No. } \\
\text { Attributed } \\
\text { to } \\
\text { Smoking }\end{array}$ & \\
\hline \multirow[t]{9}{*}{ Male } & Lung (C33-4) & $75.32 \%$ & 1549 & $50.32 \%$ & $77.82 \%$ & 1886 & $48.91 \%$ & $74.46 \%$ & 2183 & $50.91 \%$ & $72.87 \%$ & 18705 & $49.06 \%$ \\
\hline & Upper aerodigestive $(\mathrm{C} 00-15, \mathrm{C} 32)$ & $58.43 \%$ & 80 & $15.62 \%$ & $60.86 \%$ & 189 & $29.00 \%$ & $65.94 \%$ & 243 & $31.31 \%$ & $62.07 \%$ & 1802 & $27.55 \%$ \\
\hline & Stomach(C16) & $51.07 \%$ & 25 & $3.34 \%$ & $48.78 \%$ & 71 & $8.20 \%$ & $51.46 \%$ & 51 & $5.96 \%$ & $50.82 \%$ & 674 & $8.08 \%$ \\
\hline & Liver(C22) & $56.99 \%$ & 96 & $8.07 \%$ & $54.09 \%$ & 169 & $13.69 \%$ & $56.03 \%$ & 120 & $9.88 \%$ & $54.65 \%$ & 1282 & $10.11 \%$ \\
\hline & Pancreas(C25) & $51.27 \%$ & 6 & $1.78 \%$ & $53.70 \%$ & 68 & $16.30 \%$ & $52.37 \%$ & 31 & $5.61 \%$ & $52.60 \%$ & 380 & $8.36 \%$ \\
\hline & Bowel(C18-21) & $48.78 \%$ & -3 & $-0.64 \%$ & $48.02 \%$ & 60 & $8.43 \%$ & $48.03 \%$ & 10 & $1.08 \%$ & $47.64 \%$ & 250 & $3.45 \%$ \\
\hline & Kidney and other urinary $(\mathrm{C} 64-6, \mathrm{C} 68)$ & $53.17 \%$ & 7 & $5.36 \%$ & $58.38 \%$ & 46 & $25.11 \%$ & $53.91 \%$ & 26 & $10.33 \%$ & $54.26 \%$ & 253 & $13.56 \%$ \\
\hline & Bladder(C67) & $58.33 \%$ & 36 & $21.41 \%$ & $47.92 \%$ & 27 & $11.31 \%$ & $53.29 \%$ & 48 & $15.74 \%$ & $49.90 \%$ & 302 & $12.35 \%$ \\
\hline & $\begin{array}{l}\text { Myeloid } \\
\text { leukemia(C92,C93.0,C94.0,C94.2,C94.4- } \\
\text { 5) }\end{array}$ & $45.83 \%$ & 1 & $2.68 \%$ & $40.54 \%$ & -3 & $-8.84 \%$ & $43.18 \%$ & -5 & $-11.20 \%$ & $46.70 \%$ & 2 & $0.51 \%$ \\
\hline Total & & $63.96 \%$ & 1817 & $27.31 \%$ & $61.58 \%$ & 2506 & $30.59 \%$ & $63.77 \%$ & 2695 & $29.22 \%$ & $62.39 \%$ & 23709 & $28.87 \%$ \\
\hline \multirow{9}{*}{ Female } & Upper aerodigestive $(\mathrm{C} 00-15, \mathrm{C} 32)$ & $31.55 \%$ & 31 & $14.86 \%$ & $22.73 \%$ & 16 & $7.20 \%$ & $26.05 \%$ & 28 & $13.23 \%$ & $25.54 \%$ & 229 & $10.59 \%$ \\
\hline & Stomach(C16) & $19.55 \%$ & 8 & $2.33 \%$ & $15.31 \%$ & 3 & $0.70 \%$ & $14.15 \%$ & 8 & $1.96 \%$ & $15.33 \%$ & 50 & $1.27 \%$ \\
\hline & Liver(C22) & $21.33 \%$ & 26 & $4.36 \%$ & $14.95 \%$ & 0 & $0.01 \%$ & $17.10 \%$ & 25 & $5.08 \%$ & $17.60 \%$ & 171 & $3.11 \%$ \\
\hline & Pancreas(C25) & $23.71 \%$ & 22 & $7.64 \%$ & $16.71 \%$ & 11 & $2.99 \%$ & $16.13 \%$ & 19 & $4.12 \%$ & $16.15 \%$ & 84 & $2.24 \%$ \\
\hline & Bowel(C18-21) & $16.41 \%$ & -2 & $-0.51 \%$ & $14.00 \%$ & -8 & $-1.57 \%$ & $14.67 \%$ & 12 & $1.78 \%$ & $14.63 \%$ & -20 & $-0.38 \%$ \\
\hline & Kidney and other urinary $(\mathrm{C} 64-6, \mathrm{C} 68)$ & $14.29 \%$ & -4 & $-6.72 \%$ & $16.50 \%$ & 3 & $2.70 \%$ & $14.29 \%$ & 1 & $0.39 \%$ & $16.52 \%$ & 18 & $1.78 \%$ \\
\hline & Bladder(C67) & $27.27 \%$ & 5 & $9.25 \%$ & $26.32 \%$ & 9 & $12.33 \%$ & $25.00 \%$ & 9 & $9.82 \%$ & $26.12 \%$ & 80 & $10.56 \%$ \\
\hline & $\begin{array}{l}\text { Myeloid } \\
\text { leukemia(C92,C93.0,C94.0,C94.2,C94.4- } \\
\text { 5) }\end{array}$ & $5.88 \%$ & -2 & $-11.78 \%$ & $0.00 \%$ & 0 & $0.00 \%$ & $5.00 \%$ & 0 & $0.00 \%$ & $8.76 \%$ & 0 & $0.00 \%$ \\
\hline & Cervix(C53) & $14.29 \%$ & 0 & $0.13 \%$ & $11.04 \%$ & 1 & $0.52 \%$ & $10.50 \%$ & 3 & $1.69 \%$ & $11.09 \%$ & 17 & $1.07 \%$ \\
\hline Total & & $35.33 \%$ & 876 & $20.62 \%$ & $29.61 \%$ & 831 & $16.72 \%$ & $27.58 \%$ & 853 & $16.30 \%$ & $29.96 \%$ & 8648 & $17.37 \%$ \\
\hline
\end{tabular}

Table 3 Number of smoking-attributable cancer deaths and attributable fraction by age, 2010, 2014, 2019

\begin{tabular}{|c|c|c|c|c|c|c|c|c|c|c|c|c|c|}
\hline \multirow[b]{2}{*}{ Sex } & \multirow[b]{2}{*}{$\begin{array}{l}\text { Age } \\
\text { group }\end{array}$} & \multicolumn{3}{|l|}{2010} & \multicolumn{2}{|l|}{2014} & \multicolumn{3}{|c|}{2019} & \multicolumn{3}{|c|}{ Total } & \multirow[b]{2}{*}{ (\%) } \\
\hline & & $\begin{array}{r}\text { Current and } \\
\text { ever (\%) }\end{array}$ & $\begin{array}{l}\text { No. Attributed to } \\
\text { Smoking }\end{array}$ & (\%) & $\begin{array}{r}\text { Current and } \\
\text { ever (\%) }\end{array}$ & $\begin{array}{l}\text { No. Attributed } \\
\text { to Smoking }\end{array}$ & (\%) & $\begin{array}{r}\text { Current and } \\
\text { ever (\%) }\end{array}$ & $\begin{array}{l}\text { No. Attributed } \\
\text { to Smoking }\end{array}$ & (\%) & $\begin{array}{r}\text { Current } \\
\text { and ever } \\
(\%)\end{array}$ & $\begin{array}{l}\text { No. Attributed } \\
\text { to Smoking }\end{array}$ & \\
\hline \multirow[t]{4}{*}{ Male } & $35-54$ & $68.94 \%$ & 146 & $17.41 \%$ & $67.31 \%$ & 296 & $35.75 \%$ & $66.18 \%$ & 186 & $30.08 \%$ & $66.22 \%$ & 2331 & $28.55 \%$ \\
\hline & $55-74$ & $67.03 \%$ & 978 & $29.54 \%$ & $66.17 \%$ & 1591 & $36.59 \%$ & $69.83 \%$ & 1786 & $33.69 \%$ & $67.09 \%$ & 13941 & $31.80 \%$ \\
\hline & $75+$ & $58.24 \%$ & 675 & $26.93 \%$ & $53.40 \%$ & 689 & $22.85 \%$ & $53.58 \%$ & 753 & $22.82 \%$ & $54.52 \%$ & 7580 & $25.16 \%$ \\
\hline & total & $63.96 \%$ & 1822 & $27.39 \%$ & $61.58 \%$ & 2514 & $30.68 \%$ & $63.77 \%$ & 2684 & $29.11 \%$ & $62.39 \%$ & 23783 & $28.96 \%$ \\
\hline \multirow{3}{*}{ Female } & $55-74$ & $34.92 \%$ & 396 & $20.71 \%$ & $24.90 \%$ & 292 & $13.53 \%$ & $20.86 \%$ & 270 & $11.57 \%$ & $25.51 \%$ & 3214 & $14.77 \%$ \\
\hline & $75+$ & $41.01 \%$ & 467 & $24.11 \%$ & $37.68 \%$ & 527 & $21.85 \%$ & $35.86 \%$ & 564 & $21.71 \%$ & $37.56 \%$ & 5306 & $22.07 \%$ \\
\hline & total & $35.33 \%$ & 877 & $20.65 \%$ & $29.61 \%$ & 835 & $16.78 \%$ & $27.58 \%$ & 852 & $16.28 \%$ & $29.96 \%$ & 8648 & $17.37 \%$ \\
\hline
\end{tabular}

\section{Figures}



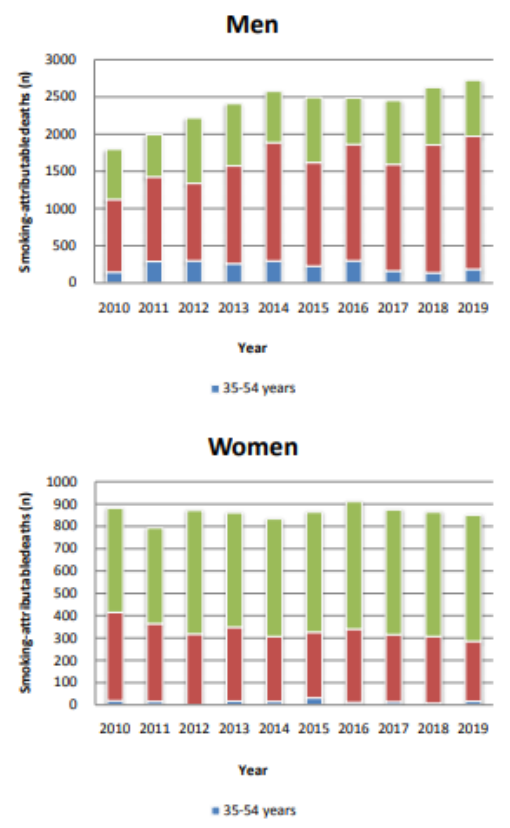

Figure 1

Smoking-attributable cancer deaths by age group, males and females, Tianjin, China, 2010-2019
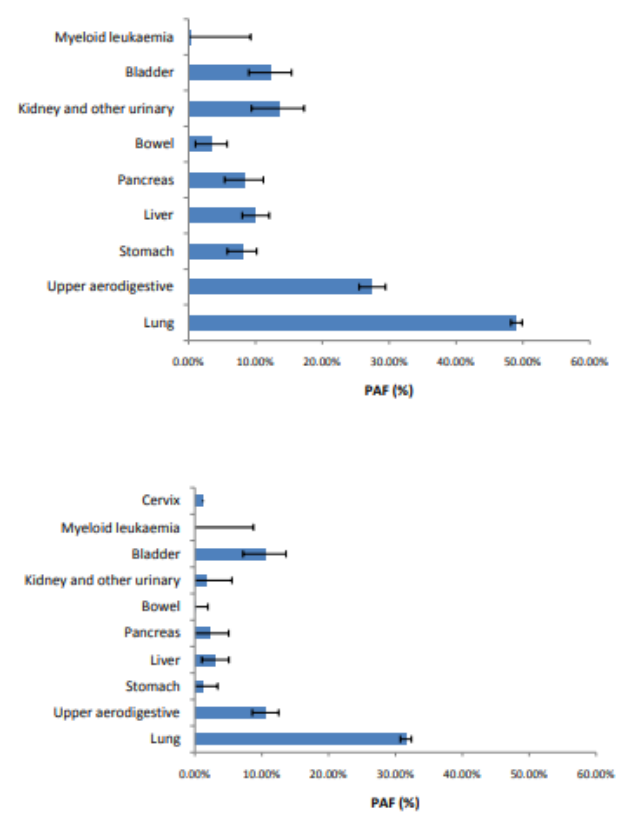

Figure 2

Sensitivity analysis of the PAF for ever-smoking using the lower and upper limits of $95 \%$ confidence interval for relative risks 